\title{
The Strategic Value of e-HRM: results from an exploratory study in a governmental organization
}

\author{
Tanya Bondarouk, University of Twente, The Netherlands \\ t.bondarouk@utwente.nl \\ Huub Ruël, University of Twente, The Netherlands \\ h.j.m.ruel@utwente.nl
}

\begin{abstract}
This paper presents results from an exploratory study in a governmental organization on the strategic value of e-HRM. By means of a questionnaire as well as through face-to-face interviews with $H R$ professionals, line managers and non-managerial employees data were collected on two generally acclaimed strategic advantages of e-HRM: changing the role of HR towards a business partner, and increasing the time available for strategic HR issues. The data presented reveals that indeed to a large extent these strategic advantages are realized, however regarding some advantages certain conditions need to be met. The results of this paper contribute to the ongoing debate on e-HRM and its strategic value.
\end{abstract}

Keywords: HRM strategic value, interviews, line managers, HRM services.

"P\&O has become dynamic, flexible, it is all true.

They are doing interesting projects, many innovative projects and ideas.

And it is always good to feel that

things are moving forward"

(from an interview with a line manager)

\section{Introduction}

Initially, in the 1970s, personnel management was seen as a suitable candidate for office automation in payroll and benefits administration and for keeping employee records $[10,17,34]$. Typically, personnel management information would be stored in simple databases and interrogated using simple key word searching. Early studies into e-HRM found only 'hesitant' use of it by HR practitioners who perceived IT as 'workhorses' of the personnel function $[1,11,13]$.

One of the first large-scale empirical studies was conducted in 1986 into the status of Human Resource Information Systems [11]), where the author concluded that the role of HRIS in the corporate management of information systems was not clear; and the topic itself was a controversial one; HRIS managers were not trained properly and lacked skills for personnel management; and HRIS planning was not well coordinated with personnel planning and the organization's strategic plans.

Strohmeier, S.; Diederichsen, A. (Eds.), Evidence-Based e-HRM? On the way to rigorous and relevant research, Proceedings of the Third European Academic Workshop on electronic Human Resource Management, Bamberg, Germany, May 20-21, 2010, CEUR-WS.org, ISSN 1613-0073, Vol. 570, online: CEUR-WS.org/Vol-570/, pp. 15-32.

(C) 2010 for the individual papers by the papers' authors. Copying permitted only for private and academic purposes. This volume is published and copyrighted by its editors. 
Since the mid-1990s, organizations have increasingly introduced electronic Human Resource Management (e-HRM) which is understood as a set of Information Technology (IT) applications that coverer "all possible integration mechanisms and contents between HRM and IT's aiming at creating value within and across organizations for targeted employees and management" [3: 507].

Recent developments in the e-HRM area are driven by rapid technological changes. Complex Enterprise Resource Planning (ERP) applications offer an integration of a broad range of HRM modules together as well as with numerous modules from other business areas such as sales, production, and finance. However, the findings from mid1980-s still have a certain familiarity. Professional reports since 2000 have indicated an increase in confidence in using e-HRM, albeit still mainly for administrative purposes. They also report that the e-HRM projects have largely remained focused on the growing sophistication of information technology $[8,9,15]$.

The literature on e-HRM suggests that, overall, the three goals of e-HRM are cost reduction, improving HR services, and improving strategic orientation [5, 23, 33]. Some empirical findings supplement these goals with globalisation as a driving e-HRM force in international large organisations (e.g. [30]). However, the findings also show that these goals are not clearly defined in practice, and that e-HRM is mostly directed at cost reduction and efficiency increases in HR services, rather than at improving the strategic orientation of HRM $[12,30,31]$. Recent studies have found that in nearly half of the companies with a completely integrated HRIS, the HR department was not viewed as a strategic partner [21].

The debate on strategic advantages of e-HRM still continues: while some researchers argue that e-HRM offers strategic opportunities to HR professionals [30], others report the absence of strategic changes due to e-HRM [14], yet another group of researchers suggests to think about special conditions when e-HRM can create strategic value for organizations and for the HRM function [24].

Driven by conflicting findings (if any) and vague theoretical ideas regarding the strategic contribution of e-HRM, this paper explores the question of what kind of strategic benefits e-HRM can and does offer to organizations.

\section{2 e-HRM and Strategic Benefits}

The literature suggests that the different goals of e-HRM, and the different types of eHRM, are expected to result in outcomes including more efficient HRM processes, a higher level of service delivery and a higher strategic contribution. Ruël et al. [29] noted an aspect that is fairly well covered by the above summary but that is nevertheless interesting to highlight, namely the changing nature of the employment relationship. With a supply shortage in the labour market (during the economic upturn of the 1990s), the individualisation of society, and the increased educational level of citizens (and thus of employees), the power balance in the employment relationship has shifted in the direction of employees: they want to set their own career paths. In the view of Ruël et al. [29], a move towards e-HRM can provide tools to support this development. This aspect adds to the earlier-mentioned drivers, such as improving service towards internal clients, but has an external societal drive.

Ruël et al. [30] have also shown that although, in practice, the e-HRM types are mixed, establishing a good basis for e-HRM at the operational level seems to be an essential prerequisite for relational and transformational e-HRM. This requires changes in the 
tasks of HR professionals (less paper-based administration, more e-communications with employees, acquiring skills for operating IT). However, positioning companies by their e-HRM types does not imply judging them - it is not about better or worse e-HRM types. Further, it was also shown that there is a 'gap' between e-HRM in a technical sense (the available functionality) and its use and adoption by employees and line managers. Actual usage/adoption can lag up to three years behind what is available [30].

Other available research evidence suggests that, in many organisations, e-HRM has led to a radical redistribution of the work that HR managers used to do. Many of the reporting activities, previously performed by HR professionals, can now be performed on-line by managers and employees [30,31]. On their own desktops, line managers have to perform appraisals, evaluate employee costs, generate HR reports (turnover, absenteeism), process training requests and oversee competence management. Employees have access to everything they need to change and manage their personal files, plan their development, process financial documents, and apply for new jobs [28].

Examination of recent e-HRM literature allows us to classify strategic benefits prescribed for e-HRM in six groups:

The generation of HR metrics to support strategic decision making [3, 16, 18, 20, 22],

The automation of routine HR tasks and replacing 'filing cabinets' [4, 26, 27],

The branding of organizations [21, 25],

Freeing HR staff from administrative burdens and allowing them to undertake strategic people-management activities [23, 25, 30, 32],

Improving talent management through e-selection, self-assessment, e-performance management [25], and

Transforming HR professionals from administrative paper handlers to strategic partners $[2,6,7,19,14,37]$.

For our study as the initial basis we have chosen two popular advantages of e-HRM, mentioned in the literature as strategic: changes in HR roles (from administrative expert - towards strategic partner), and time spent on HR administration (an assumption is that with e-HRM HR professionals spend less time on HR administration). Further, we were sensitive to the idea that in a real life case study, other 'strategic issues' as outcomes of e-HRM could be discovered. Our study, thus, was further motivated by several questions like what is perceived by organizational members as e-HRM strategic benefits. Who (strategically) benefits from e-HRM? To which extent can strategic benefits of e-HRM be achieved, and under which conditions?

\section{Method}

The study was conducted within a Belgian Federal Public Health Service, where the introduction of the e-HRM project had a seven-year history. In 1999, the Belgian Government introduced the Copernicus project as part of a thorough reform of the federal administration aiming to simplify procedures, automate administration, and improve service provision to civil servants while, at the same time, reducing their numbers.

As a key component of the Copernicus project, the HR function of the Federal Agency was reorganized. In 2005, the various HR units were integrated into one HRM department with the strategic goals of minimizing administrative HR tasks, focusing on 
value-adding HR tasks, and improving HR services for its internal customers. As a part of the HRM reorganization, an Oracle-based e-HRM system called DeBOHRA was launched in 2006 by the HRM department, following careful preparation, customization, and weekly meetings with key-users, training courses, and feedback sessions. Later, in the period June - November 2007, in preparation for the system going live for all employees, no less than 40 presentations and training sessions were held involving $68 \%$ of intended users.

\subsection{Research approach}

The research went through four stages. Stage 1 involved intensive preparation for the research. During this stage, we held presentations for the HR specialists about e-HRM studies, discussed the research design with the DeBOHRA team and the HR director at the Federal Agency, and prepared the questionnaire (March - September 2008). Stage 2 involved finalizing the questionnaire design, putting it on-line, and collecting responses (October 2008). Stage 3 concerned conducting interviews, as the follow-up data after the questionnaire. Stage 4 was dedicated to transcription of the interviews, discussion of the preliminary results, and analyzing the questionnaire, integrated with the analysis of the documents and interviews.

In conclusion, multiple research methods were applied in this project: document analysis, interviews, and a survey. Throughout the whole project we were greatly assisted by the DeBOHRA team, including its former and current leaders, members, and especially the Organization \& Development Officer. The latter coordinated all communications between the research and practice, translated the questionnaire into French, and selected respondents for the questionnaire and interviews.

\subsection{Document analysis}

We gained access to the following documents: Records of 18 presentations from the period between October 2006 and February 2008; Implementation plan of the DeBOHRA project; SWOT analysis of the DeBOHRA project; four different sets of users' manuals; documents for new users of DeBOHRA ("coaching materials"), and operationalization of the strategic HRM plans.

\subsection{Survey}

Our survey was performed between March and October 2008. To gain commitment to the research and to establish an atmosphere of mutual understanding, we presented the study four times, held two round-table sessions with the project team and the HR director, and had numerous discussions with HR specialists. In addition, we accessed the full set of related e-HRM documents such as software manuals, presentation materials, training courses materials, business case documents, progress reports, and technical descriptions of the modules. This detailed preparation allowed us to add some specific items and also modify the standard ones in the questionnaire.

91\% of the Federal Agency's staff accessed DeBOHRA. The population consists of 1236 users of DeBOHRA. From these users, a stratified random sample of 500 users was drawn that reflects the user demographics in terms of gender ( $56 \%$ female), origin (51\% Dutch language, and 49\% French language users), and educational level (44\% have been educated up to the university level, $23 \%$ had attained higher vocational education, $16 \%$ - bachelor studies, and the remaining $17 \%$ had left after high school). 
In total, we received 219 completed questionnaires indicating the $43.75 \%$ response rate with the respondents not differing significantly from the populations in terms of gender, origin, and education level. Since we had used an entry-force technique, all returned forms were fully completed with no missing values.

Scale development consisted of several stages. First, we developed a pool of items for each construct using a deductive approach. The first round content validity was assessed by independent cross-checking by six HRM experts in a survey research. The initial questionnaire was reduced and after that, back-translation into Dutch and French was done independently by two Dutch- and two French-speaking researchers, to ensure the correctness of the items [36]. These versions were checked during focus group sessions at the Federal Agency involving four DeBOHRA project team members and the HR director to insure clarity for the targeted respondents of the questionnaire.

\begin{tabular}{|l|l|l|l|}
\hline Construct & Variable & $\begin{array}{l}\text { Number of } \\
\text { items in the } \\
\text { questionnaire }\end{array}$ & $\begin{array}{l}\text { Cronbach's } \\
\text { alpha }\end{array}$ \\
& & 4 & .630 \\
Usage of e-HRM & Appropriation & 2 & .892 \\
& Frequency of use & 4 & .854 \\
\hline HRM roles & Employee Advocate & 4 & .878 \\
& Human Capital Developer & 4 & .884 \\
& Functional Expert & 4 & .866 \\
& Strategic Partner & 4 & .943 \\
\hline Time spent on HR & Role ambiguity & .933 \\
activities & Time spent on Strategic HR activities & 4 & .901 \\
& Time spent on IT-related HR activities & 4 & .618 \\
\hline
\end{tabular}

Table 1. Variables and Cronbach's alpha

Only $8.2 \%$ of the respondents had less than 1 month's experience with working with DeBOHRA; the majority (91.8\%) had been working with DeBOHRA for a longer period of time. $68.95 \%$ of the respondents have been working for the Federal Agency for longer than one year. Among respondents 140 (63.9\%) were employees; 38 (17.35\%) - HR professionals, 24 (10.96\%) - line managers, and 17 (7.76\%) - IT specialists.

All variables are measured on the 5-point Likert scale, ranging from $1=$ very low (unimportant) to $5=$ very high (important). In terms of the reliability of our measurement items, all but two of our lowest level constructs had a Cronbach's Alpha above 0.7 which indicates an acceptable reliability.

\subsection{Interviews}

Thirteen interviews were conducted with HR specialists, line managers and IT professionals, amounting to 21 hours of conversation. The interviewees were selected by the Organization \& Development Officer, who scheduled the interviews and explained the reasons to the interviewees.

Six HR professionals were invited for interviews based on three criteria: their extended experience of working with DeBOHRA, involvement in strategic HR planning, and diversity in HR operational services. The e-HRM manager and representatives of four HR activities participated in interviews: recruitment, payroll, training, and leave administration. Ten line managers were invited for interviews via e-mail, based on four 
criteria: their extended experience of working with DeBOHRA, large span of control, unusual services, and equal distribution between French and Dutch speakers. Three line managers responded positively and promptly, and they participated in interviews. Three IT specialists, who were particularly busy with DeBOHRA maintenance, were invited.

We conducted the interviews after having analyzed the data gathered through the questionnaire. The aim of such a sequential design was to elaborate on some specific findings arising from the survey. Transcripts of all interviews were sent to the respondents via e-mail for verification.

Questions were semi-structured and open, covering the main topics from the research model: Appropriation of DeBOHRA, perceived benefits from working with DeBOHRA, changes in the HR roles, and perceived effectiveness of e-HRM at the Federal Agency.

\begin{tabular}{|c|c|c|c|c|c|}
\hline & HR professionals & IT specialists & Line managers & $\begin{array}{l}\text { DeBOHRA } \\
\text { team }\end{array}$ & project \\
\hline $\begin{array}{l}\text { Number of inter- } \\
\text { views }\end{array}$ & 6 & 1 & 3 & $3^{1}$ & \\
\hline Time & $8 \mathrm{~h} 40 \mathrm{~min}$ & $1 \mathrm{~h} 30 \mathrm{~min}$ & $5 \mathrm{~h}$ & $6 \mathrm{~h}$ & \\
\hline
\end{tabular}

Table 2. Number and type of interviewees

\section{Setting the Stage: HRM and DeBOHRA}

This research was exploratory in nature; we were interested in determining whether different HR actors experienced a strategic "twist" after the introduction of DeBOHRA; and if so, what kind of. Therefore, we started with the exploration of perceived involvement in HR activities. Figure 1 allows us to compare perceptions of the respondents' involvement in HRM activities. Line managers expressed that they were mostly busy with organizational development including career opportunities, career planning and development, individual development cycles and personnel planning. Managing the workforce is the activity performed most often. It includes planning, recruitment and selection, promotion, contract management and retirement policies and procedures. It can be linked to the organizational change happening at the Federal Agency: HR professionals take on more strategic roles and are involved in strategic planning of the workforce. Employees noticed that for them, the work with DeBOHRA seemed the HR activity performed most often from the list. It confirms the meaning of e-HRM in organizations - to devolve HR responsibilities for the individual data administration to the employees themselves. 


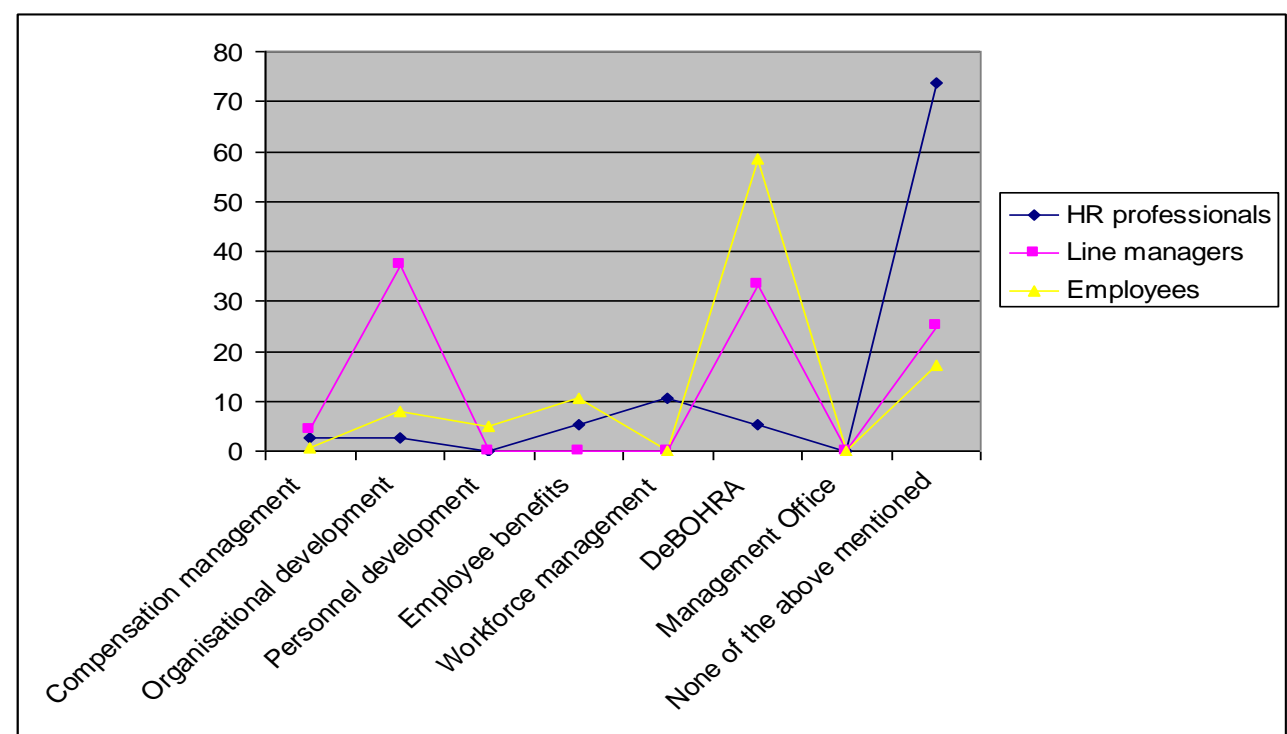

Figure 1. Perceived involvement in HRM activities by HR professionals, line managers, and employees

\begin{tabular}{lcc}
\hline \multicolumn{1}{c}{ Type of e-HRM transaction } & $\begin{array}{c}\text { Number of } \\
\text { transactions }\end{array}$ & $\begin{array}{c}\text { Percentage } \\
\text { of total }\end{array}$ \\
\hline Application for internal training programs & 1441 & $51.17 \%$ \\
Application for external training programs & 747 & $26.52 \%$ \\
Application for biking compensation payment & 174 & $6.18 \%$ \\
Changing address & 102 & $3.61 \%$ \\
Changing work scheme & 96 & $3.43 \%$ \\
Changing basic personnel data & 94 & $3.34 \%$ \\
Application for paid services & 39 & $1.35 \%$ \\
Changing family status and contact persons & 34 & $1.19 \%$ \\
Recognition of educational level, language proficiency & 27 & $0.95 \%$ \\
Diploma recognition & 19 & $0.68 \%$ \\
Application for vocational training leave & 19 & $0.68 \%$ \\
Training evaluation & 14 & $0.50 \%$ \\
Recognition of success of exams SELOR & 5 & $0.20 \%$ \\
Application for a badge & 3 & $0.11 \%$ \\
Application for the birth allowance premium & 2 & $0.09 \%$ \\
Application for diploma recognition $\quad \boldsymbol{T O T A \boldsymbol { L }}$ & 0 & $0.00 \%$ \\
& 2816 & 100 \\
\hline
\end{tabular}

Table 3. An overview of DeBOHRA e-transactions / sampled employees

Our next step in setting the stage for the research was to investigate applications and HR tools offered by DeBOHRA. Important was also to figure out how intensively respondents worked with DeBOHRA. 


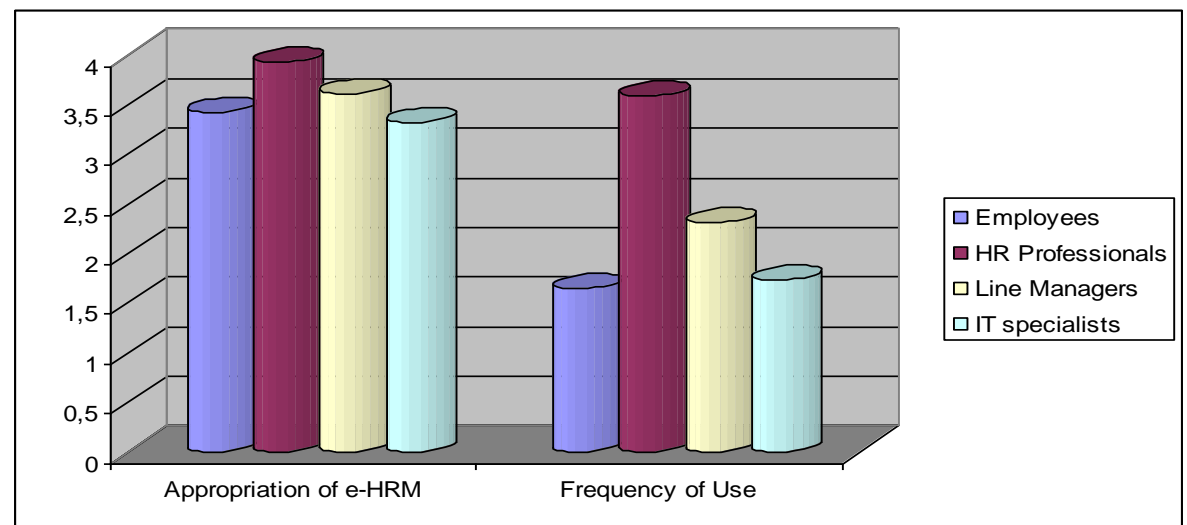

Figure 2. Perceptions of respondents about usage of e-HRM

DeBOHRA (Oracle based) contains various modules that offer HR applications such as managing personnel data, training and development, recruitment and selection, personnel planning, e-learning, HR report generation, holiday administration, workflow registration, and payroll management. Of the 1236 employee-users of DeBOHRA, 126 employees never logged onto the system (10.2\%), indicating that $89.8 \%$ had logged onto DeBOHRA at least once. Table 3 reports the usage of DeBOHRA by the users selected for this study, and further details of $16 \mathrm{HR}$ activities performed by those users in DeBOHRA. There were 2816 electronic transactions registered in DeBOHRA in the period July 2008 - October 2009. On average, the employees used DeBORAH 8.8 times. Overall, $91 \%$ of the Federal Agency's staff had access to DeBOHRA.

The data from data-base was triangulated with the survey results. Usage of DeBOHRA was assessed in the questionnaire by the respondents' perceptions of two dimensions: appropriation of DeBOHRA and frequency of use (the amount of actual use perceived by users). The data were also compared with the objective transactions administration.

As Figure 2 illustrates, all respondents perceive that they appropriate DeBOHRA very well (mean varies from 3.3 to 3.9). This shows that they work with DeBOHRA in the way it was intended to be used, and perceive that they use it in an optimal way. The amount of actual usage is perceived as lower than appropriation by employees (mean $=$ $1.650)$, line managers $($ mean $=2.313)$, and IT specialists $($ mean $=1.735)$.

\section{Strategic Benefits of DeBOHRA}

\subsection{DeBOHRA and Changes in HRM Roles}

HR roles are usually considered norms and expectations that govern the behavior of HR professionals. We could not make strong differences between four HR roles [35]. However, the differences between "People" and "Business" orientation in the HR profession were clearly visible in the descriptive statistics. This is in line with the results of the Explorative Factor Analysis . 


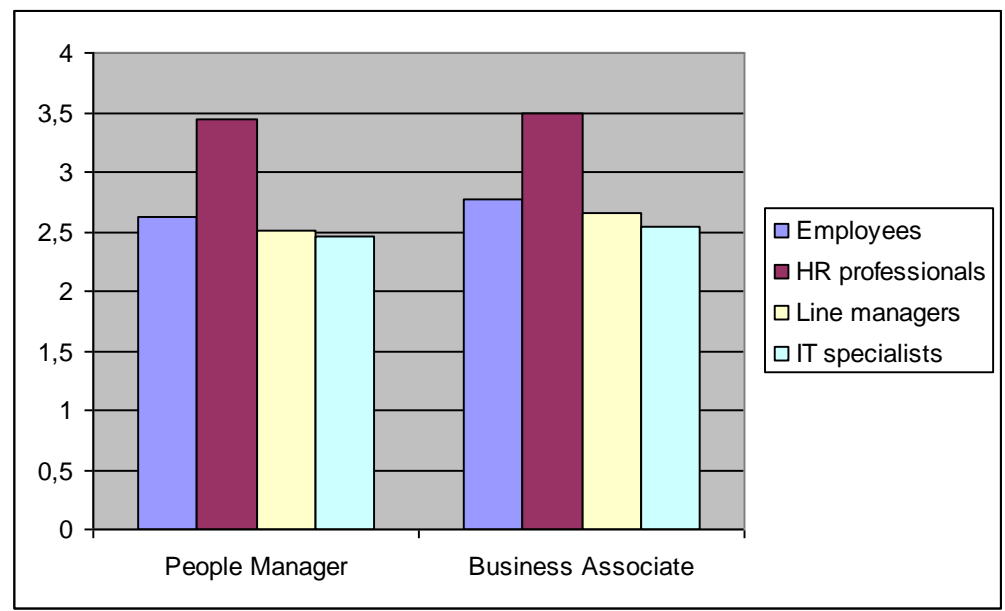

Figure 3. Perceptions of respondents about two HR roles performed by the HR professionals

The EFA revealed two factors, reducing 4 roles into 2, the business associate and the people manager Further, the following observations were made:

The respondents score both HR orientations - business and people - as equally important, with a slight predominance for Business Associate.

The HR professionals see their own roles more clearly and distinctly than other respondents.

Employees perceive HR professionals as Business Associates $($ mean $=2.76)$ slightly more than as People Managers (mean $=2.62)$.

Line managers also perceive HR professionals more as Business Associates (mean = 2.65) than as People Managers (mean $=2.50)$.

Interviewees felt that the introduction of DeBOHRA did not change the HR roles and responsibilities at the Federal Agency. HR specialists did not see their work becoming easier. For example, the HR specialists described:

"People who were busy with HR administration five years ago - they still do the same. New HR employees are mostly busy with strategy and policies. But that is due to our new HR director and not due to DeBOHRA." (HR sp-1)

"My tasks did not become easier, maybe only making reports and checking the data go easier. But talking about my main responsibility - staffing plan - it is as intensive as without DeBOHRA.” (HR sp-3)

At the same time, all interviewees acknowledged changes in the vision of the HRM department. They see it as becoming more strategic, oriented towards people and organization development. However, attributing an HR strategic orientation to the introduction of DeBOHRA seems to be unsound. Most of all, interviewees attributed such a re-orientation to the new envisioning of the HRM work at the Federal Agency, and particularly to the HRM director and his highly effective and respected leadership. One of the HR professionals described it:

"Nowadays I think that our P\&O department plays a more strategic role than ever before. $\mathrm{P} \& \mathrm{O}$ is becoming strategic. At the same time, given the FOD work environment, such changes go too quickly. People have different knowledge, expectations, and experience. I often hear that it is a 'long-life change'. Myself I do not think it is bad, but some people find it too quick." (HR sp-3) 
Line managers also expressed changes they experience as a result of the whole reconstruction of the HRM: new roles, new responsibilities. And there is a clear commitment to these changes:

"I see lots of advantages compared to the situation of $\sim 10$ years ago... There are a lot of changes. Now we have to be busy with management of people, budgeting, planning, etc. I have 3-, 6-year plans, for example. Our targets are high: sustainability and mobility. We determine the goals, and the $\mathrm{P} \& \mathrm{O}$ helps us further. We get guidelines from P\&O or the board." (Line man-3)

An HR specialist emphasizes:

"We are very much up-front. The HR Director is a fantastic leader! He is a driver of this change! I am very glad that we are pushing ahead and in front of other ministries. I like it much more than only administration, to be a pioneer in HRM." (HR sp-4)

The e-HRM manager summarizes:

"I feel that we work now very differently from the past. We discuss concepts, rules, policies, and less administration." (HR sp-5)

All in all, the respondents did not see big changes in the HR roles or HR responsibilities as a result of the introduction of DeBOHRA (from the questionnaire and interviews). However, both groups of respondents, HR specialists and line managers, acknowledged that extensive changes have happened to the HR management at the Federal Agency. HRM has become more strategic, in their view, due to the whole program of HRM reenvisioning.

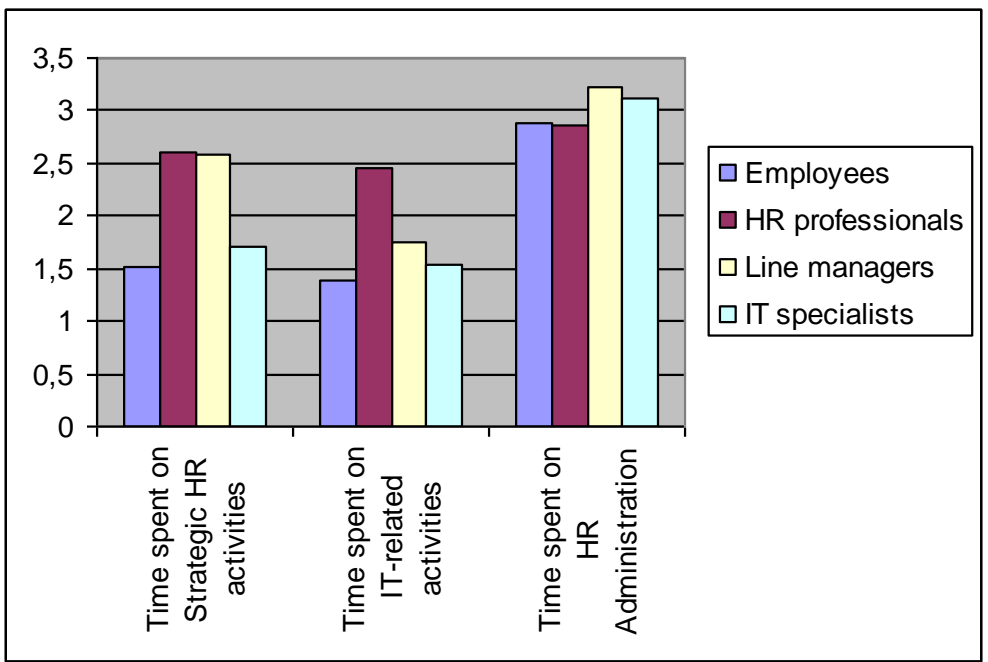

Figure 4. Perceptions of respondents about time spent on $H R$ activities after the introduction of DeBOHRA

\subsection{DeBOHRA and Changes in Time Spent on Different HR Activities}

Figure 4 allows observe that all respondents perceive that since the implementation of eHRM, they spend most of their time on HR administration (checking, recording and organising personnel data). Line managers score the highest on amount of time spent on HR administration since the introduction of e-HRM. HR professionals score the lowest on the time spent for HR administration. Time spent on strategic HRM activities (forecasting employees' needs, matching job vacancies with the organizational needs, developing long-term HR policies) is perceived by both HR professionals and line managers as the second greatest time-consuming HR activity (since the e-HRM 
introduction). It also echoes the latest strategic developments at the Federal Agency. The maintenance of DeBOHRA and other e-HR applications is not perceived as time consuming by line managers, employees, and IT specialists. HR professionals indicated that they spend more time on these activities than other groups of respondents, although it remains the lowest time-consuming activity.

The opinions of interviewees fell into two groups: those who did not see differences, and those who noticed a lot of time saving due to the introduction of DeBOHRA.

"In my view, it does save time. If in the past 30 people had a salary increase, we had to change the salary steps 30 times. Now, with the basic data, the list is in DeBOHRA, and it makes changes automatically. At the beginning people were not motivated to make this list. Now they see - if they have good information, it helps. It takes time to explain and convince people to use it. Time saving is in my view the great benefit." (HR sp-1)

For line managers, on the contrary, the introduction of DeBOHRA is perceived as partial devolution of the HR tasks to them. They might see it as time-consuming, as one of them said:

\footnotetext{
"At the same time I feel that line managers do more and more HR tasks that were done by the P\&O department before. It is not always very pleasant but has to be done. I can imagine that it is an evolution of the whole organization." (Line man-2)

“DeBOHRA doesn't support all of our HR policies and responsibilities yet. To take, for example, personnel development circles. I have to spend about 2 full days per employee to work on their evaluation, planning and development plans for the next year because all of this still has to be done on paper. Too time consuming and not flexible at all." (Line man-2)
}

The e-HRM manager stressed the importance of changes in the content of spending time instead of simply saving it:

"The idea is that we spend less time on routine tasks and more on guiding tasks, to partner with line managers. In 2002 we had 80 FTE, now 60.” (HR sp-5)

The descriptive statistics show some differences in the ways respondents spend time on HR-related activities. However, overall we cannot conclude that the introduction of DeBOHRA significantly affects/changes the time spent. During the interviews we observed that the respondents had diverse opinions regarding this issue. First, HR pro's do see time savings in digitalization and moving away from paperwork but stress the shift in time spending (from administration towards 'guiding' tasks); line managers perceive that they spend more time on HR than before.

\section{Overall Perceived Benefits from DeBOHRA}

\subsection{Conditional Benefits}

Interviewees talked about so-called "conditional" benefits: time saving, strategic reorientation, and better collaboration with other departments. It could all be achieved if certain conditions are met. For example,

Time saving will be apparent if all modules and all IT's are integrated in one, inclusive e-mail traffic. Saved time could be spent on policy-making and strategic activities:

"Furthermore, I think that we have to do more to get more results out of DeBOHRA. Currently, a lot goes through the e-mail correspondence. It could be all in DeBOHRA. If we save time on e-mails, we could use the freed time for policy-making, reorganizing of the processes, improving our collaboration with the salary-providing 
company, developing tools for calculation of the net salaries, more integration with the social departments." (HR sp-1)

One condition mentioned by many interviewees was users' readiness to work with DeBOHRA. If all users were geared to an advanced usage level, all expected benefits will appear (as expressed by the respondents):

"At the moment only those who are working at the administrative level win time from using DeBOHRA. But they are not qualified to accomplish DeBOHRA projects. You need to train them, invest in people. So, first thing to do is to up-grade people." (HR sp1)

"P\&O professionals are not always competent to work with DeBOHRA. If you use such an application, you have to be PC literate." (HR sp-2)

"I feel that we can be still more pro-active. We could work better with IT. Our image of HRM would be even stronger." (HR sp-4)

Moreover, involvement of line managers in the HRM processes requires them to acquire new analytical skills. To obtain all the benefits of e-HRM, you need to raise line managers to another managerial / analytical level:

"I have used many DeBOHRA applications, and I think it is interesting. Mostly, we perform statistical analysis with DeBOHRA. It could enable us to make in-depth analyses of ROI, strategic orientation, service improvement. But for this you again need new skills - analytical. In my view, not all managers have such skills. Moreover, they need to think strategically, to broaden their mind-set, to switch to other personnel goals." (HR sp-2)

- Although the usefulness of orderly information was acknowledged, HR professionals saw a possibility to gain more benefits from, for example, better utility of a report generator application:

"Till now DeBOHRA did not help to save time as we have to print many papers to make reports. In the future I believe if a report generator works better, it will help much more, but now we still produce many documents manually." (HR sp-4)

- There was understanding of the strategic possibilities IF the DeBOHRA implementation is completely successful:

"If it works, then I foresee my future as being busy with: steering a HR project, working on competencies development" (HR sp-4).

\subsection{Realized benefits}

Many interviewees noted benefits from using DeBOHRA without any conditions, socalled 'benefits-in-use'. Collection of their expressions reflects the aggregated value of use of DeBOHRA. DeBOHRA contributes to the image of the HRM department.

"We are trying to be a modern HR brand. There are other ministries that do not have an 'organization' group within their HRM department." (HR sp-5)

“P\&O department doesn't always have a very good symbol / image in an organization. When people talk about P\&O, usually they talk about paying salaries. DeBOHRA might improve and change such an image. For example, if you need to, you can quickly communicate your problems and get a rapid response. It contributes to the image." (HR $\mathrm{sp}-2)$

"I think that with DeBOHRA, P\&O has become more 'open' to the employees. We get more insight into a lot of the business and actions that are being taken by P\&O." (IT $\mathrm{sp}-1)$

DeBOHRA is a tool that helps the company to realize a new way of doing HRM. HR specialists participate in strategic and analytical discussions instead of being busy with 
just the salary administration. Thus, e-HRM improves the professionalization of the HR specialists.

"I feel that we work now very differently from in the past. We discuss concepts, rules, policies, and less administration. It is not easy to explain to all HR colleagues, mostly we benefit from others' work. Benefits I see are: professionalization of the HR function, strategic discussions, and analytical discussions." (HR sp-5)

HR administration runs more easily, with possibilities for orderly information.

"Anyway, we see certain benefits from DeBOHRA. Definitely, the administration runs more easily as there is a link with, for example, the position of people in the organization. If we recruit somebody, we see immediately overviews of similar positions. We also see directly how diverse our workforce is, and whether we should work further on this issue: gender, language, handicaps, etc." (HR sp-3)

Administrative HR tasks are mostly automated, allowing for less paper work, more transparency and sharing of information.

\begin{abstract}
"An advantage is that certain HR administrative tasks get automated, less paper work, documents can be shared and centralized. Everything can be done within one system. No need to have contacts with $\mathrm{P} \& \mathrm{O}$ for every small administrative question. $\mathrm{P} \& \mathrm{O}$ tries to keep a "Q\&A" section up-dated, too. If we have to ask for a reimbursement for example, it is just a few clicks now, no need to search for many documents as we did earlier. To change your address is the same - very easy." (IT sp-1)
\end{abstract}

Orderly information in DeBOHRA makes it possible for HR specialists to participate in strategic workforce planning.

"I have an overview of the workforce, then I also take recommendations from FOD $\mathrm{P} \& \mathrm{O}$ concerning personnel planning (levels, functions, diversity, etc., and after that I make vacancy plans." (HR sp-3)

"Thanks to DeBOHRA, the board now discusses HR issues on another level. Today I presented a balance-score card to all $\mathrm{P} \& \mathrm{O}$ directors of all ministries. It's easy to make a balance-score card now. e-HR makes it much more modern." (HR sp-5)

Orderly information in DeBOHRA makes it possible for HR specialists and line managers to manage employee performance objectively.

'DeBOHRA = transparency: all jobs are now 'officially' function-matched and not people-matched, which is useful to map career opportunities and objectify promotions. It became more visible with DeBOHRA. At least with DeBOHRA, performances of people can be objectively evaluated. It is very good." (Line man-2)

DeBOHRA is seen as a means to make HRM more efficient. At the moment there are $60 \mathrm{HR}$ specialists working for almost 2000 employees at the Federal Agency.

"At the moment there are 60 employees in the HRM department working for 2000 workers. A norm for the public sector is 1:60, but here we have 1:33." (HR sp-5)

\title{
7 Strategic Benefits from DeBOHRA: Quantitative and qualitative data combined
}

\begin{tabular}{l|l}
\hline Perceived benefits & $\begin{array}{l}\text { Perceived status of } \\
\text { benefits }\end{array}$ \\
\hline $\begin{array}{l}\text { Improved image of the HRM department and HR professionals } \\
\text { Perceptions about uniqueness of the HRM }\end{array}$ & $\begin{array}{l}\text { Realized } \\
\text { Realized } \\
\text { Facilitating a new way of "doing HRM" and professionalization of the } \\
\text { HRM function }\end{array}$ \\
Rnabling strategic and analytical HRM discussions \\
HRM-related information is orderly and transparent & Realized \\
Enabling sharing of HRM-related information & Realized \\
\hline
\end{tabular}




\begin{tabular}{l|l}
\hline HR administration is easier than without e-HRM & Conditional \\
Enabling and simplifying strategic workforce planning & Conditional \\
Enabling, objectifying, and simplifying strategic performance man- & Realized \\
agement & \\
Strategic re-orientation of HR professionals & Conditional \\
Time saving for HR pro's by reducing HR administration & Conditional \\
\hline
\end{tabular}

Table 4. Overview of the realized and conditional benefits perceived from using DeBOHRA

The results from the quantitative and qualitative studies combined leads to the following picture: the implementation of DeBOHRA has resulted in an improved image of the HRM department and HR professionals, it has contributed to perceptions of the unique character of HRM within the ministry, it has facilitated a new way of 'doing HRM' and contributed to the professionalization of the HRM function, it has enabled strategic HRM discussions, it has lead to more orderly and transparent HRM information, it has enabled the sharing of HRM-related information, and it has enabled objectifying and simplifying strategic performance management.

Only if certain conditions are met (e.g. integration of tools, user readiness, line manager involvement), the implementation and use of DeBOHRA will make HR administration easier, it will enable simplifying strategic workforce planning, it will enable the strategic re-orientation of HR professionals, and it will save time for HR professionals.

We summarize in Table 4 the integrated overviews of statistical and interview-based data regarding potential (conditional) and realized benefits from working with DeBOHRA at the Federal Agency, and conditions for their realization and further enhancement.

\section{Lessons Learnt}

\subsection{Success of DeBOHRA Implementation}

The implementation of DeBOHRA should be considered a successful project for three reasons:

- More than $90 \%$ of the people working for the Federal Agency are using DeBOHRA.

- The acceptance rate of the technology is very high. Perceived appropriation ranges from 3.3. to 3.9 (5-point scale, $5=$ the strongest appropriation), meaning that the users work with DeBOHRA as they are supposed to.

- Users are competent to work with DeBOHRA.

\subsection{Net Benefits of DeBOHRA}

Research has revealed that the implementation of DeBOHRA (= high level of its use and appropriation) leads to sound benefits for the Federal Agency:

- High level of perceived uniqueness of the HRM at the Federal Agency by all stakeholders.

- Brand management of the organization as a whole and its Human Resource Management.

- Enhancing of a "new way of doing HRM": 
- HR professionals see themselves more as HR advisors than administrators

- Line managers and employees perceive HR specialists more as Business Associates than People Managers

- Line Managers get more involved in (Strategic) Personnel Management

- Employees take responsibility for some HR administration

- Improving HR information management:

○ Transparency of HR-related information

○ Sharing of HR-related information

- Enabling Strategic HRM:

- Enabling strategic and analytical HRM discussions

○ Strategic workforce planning

○ Strategic organizational and employees' performance management

○ Strategic re-orientation of HR professionals

- $\quad$ Simplifying administrative HR processes.

Conditions for DeBOHRA benefits realization / enhancement

Increasing ease of use of DeBOHRA applications, good and prompt communication about improvements and challenges

Matching of all information technologies

Increasing intrinsic data quality in DeBOHRA

Increasing visibility of HR practices, more communication

Improving comprehensibility of HR policies, more explanation

Employees' involvement in the DeBOHRA projects (more than just informing)

Increasing analytical skills of line managers and HR pro's

Technology should work well, and all modules should be integrated

Communicating to the users both the advantages and limitations of DeBOHRA

Increasing the usability of a report generator

Table 5. Overview of conditions for enhancing benefits from using DeBOHRA

Two facts advocate the efficiency gains from using DeBOHRA:

- Reduction of the number of HR professionals (ratio is 1:33)

- Partial, perceived reduction of time spent on HR administration.

However, it is difficult to draw conclusions about the total financial overview as a result of DeBOHRA implementation from this research. Such an overview may include many aspects like training, maintenance, new DeBOHRA projects, upgrading, interface changes, Oracle license, line managers' involvement, etc.

Line managers deem DeBOHRA benefits less positive than HRM specialists. On the one hand, this is understandable as they feel it is taking over their HR tasks. On the other hand, it indicates that the visibility, comprehensibility, and distinctiveness of HRM policies and practices should become clearer for line managers. 
User participation is a well-acknowledged factor affecting people's commitment to an IT (e-HRM). In IT research, user participation is usually recorded as the activities and behaviors of potential users in an IT project. Line managers and employees score their participation in the project as low. A lot has been done by the e-HRM project team to inform the users of DeBOHRA about its intentions, functionalities, and progress. At the same time, research has shown that the intensity and extent of users' responsibilities and hands-on activities in the DeBOHRA project are characterised as "symbolic participation" and "participation by advice". This means that users are informed about the project (at the risk of having information overload!), and they participate in the project groups. But their advice / inputs are limited due to different circumstances, including legitimacy and empowerment issues. Our advice is to involve users in participation by doing: create DeBOHRA sub-projects in the future to empower line managers, employees and HR pro's to take decisions.

\section{Discussion: The Ongoing Debate on e-HRM and its Strategic Valuel}

As put forward in the introduction of this paper, the debate on e-HRM and its strategic value has not been conclusive: does e-HRM create strategic value? and how does it create value, if it does so. The literature presents different schools of thought on this issue, however the results presented in this paper support the school that believes that eHRM does create value. Although we are aware of the critique one can have on the methodology used, which mainly investigates perceptions, we believe that it is relevant and useful to use perceptions as a data source. As we combined systematic - structured measurement procedures such as a questionnaire with face-to-face interviews, the research method allowed opposing views and perceptions to emerge.

However, we invite new studies in other types of organizations to make new contributions to the debate on e-HRM and its strategic value.

\section{References}

1. Ashbaugh, S., \& Miranda, R. (2002). Technology for human resources management: Seven questions and answers. Public Personnel Management, 31, 7 -16 .

2. Bell, B.S., Lee, S.-W., \& Yeung, S.K. (2006). The impact of e-HRM on professional competence in HRM: implications for the development of HR professionals. Human Resource Management, 45 (3), 295 - 308.

3. Bondarouk, T., \& Ruël, H. (2009). Electronic Human Resource Management: challenges in the digital era. International Journal of Human Resource Management, 20 (3), 505 - 514.

4. Brown, D. (2002). eHR - victim of unrealistic expectations. Canadian HR Reporter, 15 (5), 1.

5. Brockbank, W. (1997). HR's future on the way to a presence. Human Resource Management, 36 (1), 65 - 70.

6. Broderick, R., \& Boudreau, J.W. (1992). The evolution of computer use in human resource management: interviews with ten leaders. Human Resource Management, 30 (4), 485 - 508. 
7. Burbach, R., \& Dundon, T. (2005). The strategic potential of Human Resource Information Systems: Evidence from the Republic of Ireland. International Employment Relations Review, 11 (1/2), 97 - 117.

8. CedarCreastone (2006). CedarCrestone 2006 Workforce Technologies and Service delivery approaches Survey, $9^{\text {th }}$ Annual edition, Cedar Crestone.

9. CedarCrestone 2008 -2009 HR Systems Survey, $11^{\text {th }}$ Annual Edition.

10. Cheek, L. (1971). Personnel Computer Systems: solutions in search of a problem. Business Horizons, 14 (4), 69 - 76.

11. DeSanctis, G. (1986). Human Resource Information Systems: a current assessment. MIS Quarterly/ March, 14 - 27.

12. Gardner, S.D., Lepak, D., \& Bartol, K.M. (2003). Virtual HR: the impact of information technology on the Human Resource professional. Journal of Vocational Behaviour, 63, $159-179$.

13. Groe, G.M., Pyle, W., \& Jamrog, J.J. (1996). Information Technology ad HR. Human Resource Planning, 19 (1), 56 - 61.

14. Haines III, V.Y., and Lafleur, G. (2008), Information Technology usage and Human Resource roles and effectiveness. Human Resource Management, 47 (3), 525-540.

15. HayGroup (2002). E-HR: a new way of value creation. HayGroup, Philadelphia.

16. Hendrikson, A.R. (2003). Human Resource Information Systems: backbone technology of contemporary human resources. Journal of Labor Research, 24 (3), 381 $-394$.

17. Hennessey, H.W., Jr. (1979). Computer applications in Human Resource Information Systems. Human Resource Planning, 2 (4), 205 - 213.

18. Hussain, Z., Wallace, J., \& Cornelius, N.E. (2007). The use and impact of human resource information systems on human resource management professionals. Information \& Management, 44 (1), $74-89$.

19. Keegan, A., \& Francis, H. (2008). HRM, technology and strategic roles: considering the social implications. In: G. Martin, M. Reddington, \& H. Alexander (Eds.): Technology, Outsourcing and Transforming HR (pp. 421 - 447), Elsevier, Amsterdam.

20. Lawler, E.E., Levenson, A., \& Boudreau, J.W. (2004). HR metrics and analytics : use and impact. Human Resource Planning, 27 (4), 27 - 35.

21. Lawler, E.E., \& Mohrman, S.A. (2003). HR as a strategic partner: What does it take to make it happen? Human Resource Planning, 26, 15 - 29.

22. Lengnick-Hall, M.L., \& Moritz, S. (2003). The impact of e-HR on the Human Resource Management function. Journal of Labor Research, 24 (3), 365 - 379.

23. Lepak, D.P., \& Snell, S.A. (1998). Virtual HR: strategic human resource management in the $21^{\text {st }}$ century, Human Resource Management Review, 8 (3), 215 234.

24. Marler, J. (2009). Making human resources strategic by going to the Net: reality or myth? International Journal of Human Resource Management, 20 (3), 515 527. 
25. Martin, G., Reddington, M., \& Alexander, H. (2008): Technology, Outsourcing and Transforming HR. Elsevier, Amsterdam.

26. Martinsons, M.G. (1994). Benchmarking human resource information systems in Canada and Hong Kong. Information \& Management, 26 (6), 305 - 316.

27. Parry, E., Tyson, S., Selbie, D., \& Leighton, R. (2007). HR and Technology: Impact and Advantages. London: Charted Institute of Personnel and Development.

28. Roehling, M.V., Boswell, W.R., Caligiuri, P., Feldman, D., Graham, M.E., Guthrie, J.P., Morishima, M., \& Tansky, J.W. (2005). The future of HR management: research needs and directions. Human Resource Management, 44 (2), 207 - 212.

29. Ruël, H.J.M., Looise, J.C., \& Bondarouk, T. (2002). E-HRM: een verschijnsel nader in kaart gebracht. De ontwikkeling van een model voor praktijk en onderzoek.[e-HRM: a phenomenon observed more closely: developing a model for practice and research] Tijdschrift voor HRM. [Journal of HRM] winter 2002.

30. Ruël, H.J.M., Bondarouk, T.V., \& Looise, J.C. (2004). E-HRM: innovation or irritation. An exploration of web-based Human Resource Management in large companies. Lemma Publishers: Utrecht.

31. Ruta, C.D. (2005). The application of change management theory to the HR portal implementation in subsidiaries of multinational corporations. Human Resource Management, 44 (1), 35 - 53.

32. Shrivastava, S., \& Shaw, J.B. (2004). Liberating HR through technology. Human Resource Management, 42, $201-222$.

33. Stanton, J.M., \& Coovert, M.D. (2004). Turbulent waters: the intersection of information technology and human resources. Human Resource Management, 43 (2), 121- 126.

34. Tomeski, E.A., \& Lazarus, H. (1974). Computerized Information Systems in personnel - a comparative analysis of the state of the art in government and business. Academy of Management Journal, 17 (1), 168 - 172.

35. Ulrich, D. (1997). Human Resource Champions. Harvard Business School Press.

36. Usunier, J.-C. (1998). International and Cross-Cultural Management Research, London: Sage.

37. Voermans, M., and Veldhoven, M. Van (2007). Attitude towards e-HRM: an empirical study at Philips. Personnel Review, 36 (6), 887 - 902. 